\title{
Dermatofibroma protuberans: Report of a case
}

\author{
ROBERT A. NORMAN, D.O. \\ Arlington, Massachusetts \\ JOSEPH BENNETT, D.O. \\ CHRISTIAN G. DREHSEN, M.D \\ Seminole, Florida \\ BRUCE DEEM, D.O \\ Tampa, Florida
}

\author{
Dermatofibroma \\ protuberans is a cutaneous neoplasm \\ that tends to recur locally after excision. \\ The case reported here illustrates \\ typical features of history, clinical \\ characteristics, and histologic \\ appearance. The local aggressiveness of \\ the neoplasm and the lack of \\ effectiveness of radiation makes wide \\ local excision mandatory.
}

Dermatofibroma protuberans is an uncommon tumor with characteristic clinical features and a tendency for local recurrences after surgical excision. It is typically a cutaneous neoplasm that looks like an infected keloid. Unless the physician suspects the nature of the tumor, it may be misdiagnosed and inadequately excised. ${ }^{1}$

\section{Report of case}

A 29-year-old black man was seen on an outpatient basis on October 1986 with a primary complaint of excessive burning of the right eye. The patient was evaluated and diagnosed as having Bell's palsy. Further examination revealed a $4 \times 6$ hyperemic growth in the abdominal region.

The patient's past medical history was essentially unremarkable. He had no known allergies, and was taking no medications. The patient stated that the growth had been present for 1 month. He denied previous abdominal trauma. His job, in a defense plant, required exposure to trichloroethene and alcohol.

The patient was treated on a trial basis, being placed on a regimen of amoxicillin, $250 \mathrm{mg}$. four times a day for 2 weeks, because of the possibility of an abscess formation in this region. The growth resembled an infected keloid. $\mathrm{He}$ had also been on prednisone, $5 \mathrm{mg}$. twice daily, for Bell's palsy, which was stopped prior to hospitalization.

The initial surgical treatment consisted of a biopsy. The specimen revealed histologic findings consistent with those of dermatofibroma protuberans, and surgical excision was recommended.

The patient was subsequently admitted to University General Hospital and prepared for surgery the following day. At the time of admission, the oral temperature was $97.6 \mathrm{~F}$. The pulse rate, respiratory rate, and blood pressure were normal. Results of physical examination of the heart, lungs, genitalia, extremities, and cranial nerves were within normal limits. Examination of the thoracoabdominal wall revealed a $4 \times 6 \mathrm{~cm}$. mass, which resembled a keloid formation, and several satellite lesions.

Routine laboratory studies on admission revealed the following hematologic values: leukocyte count, 7,000/ cu.mm.; erythrocyte count, 4.61 million/cu.mm.; hemoglobin, $14.4 \mathrm{gm} . / \mathrm{dl}$; hematocrit, $42.4 \mathrm{ml} . / \mathrm{dl}$., $35 \mathrm{seg}$ mented cells, 1 band form, 55 lymphocytes, 6 monocytes, and 3 eosinophils. The prothrombin time was 13 seconds (11.9 control). A partial thromboplastin time was 33.7 seconds (25.4 control). A rapid plasma reagin was nonreactive. Results of a serum profile were essentially within normal limits except for elevated phosphorus level $(5.5 \mathrm{mg} . / \mathrm{dl}$.$) , and elevated total protein (8.0 \mathrm{gm} / \mathrm{dl}$., with normal, 6.5 to 8.0). Serum protein electrophoresis yielded essentially normal results, as did the urinalysis.

A bone scan revealed a small amount of increased activity overlying the right hip, in the anterior projection only, but this was thought to be artifact rather than true increased activity within the bony structures. The electrocardiogram showed a normal sinus rhythm with a suggestion of incomplete right bundle branch block and nonspecific ST-T wave changes.

At surgery, after the patient was placed under general anesthesia, a large panel of tissue measuring $16 \times 8 \mathrm{~cm}$. was excised. The panel consisted of skin, subcutaneous fat, fascia, and underlying rectus and external oblique muscle. Specimens were prepared for pathologic examination. The resultant defect was closed by a split-thickness skin graft (Figs. 1 and 2).

The patient tolerated the operation well, and had no postoperative complications. The hospital course progressed satisfactorily. The patient was allowed to return home in 6 days, to be followed closely on an outpatient basis. He did not receive postoperative radiotherapy or chemotherapy. He was lost to follow-up.

\section{Review of literature}

Dermatofibroma protuberans occurs primarily in early adulthood or early middle age.$^{1-5}$ Men are afflicted more often than women. ${ }^{3-5}$ The most common location for this lesion is on the trunk or prox- 


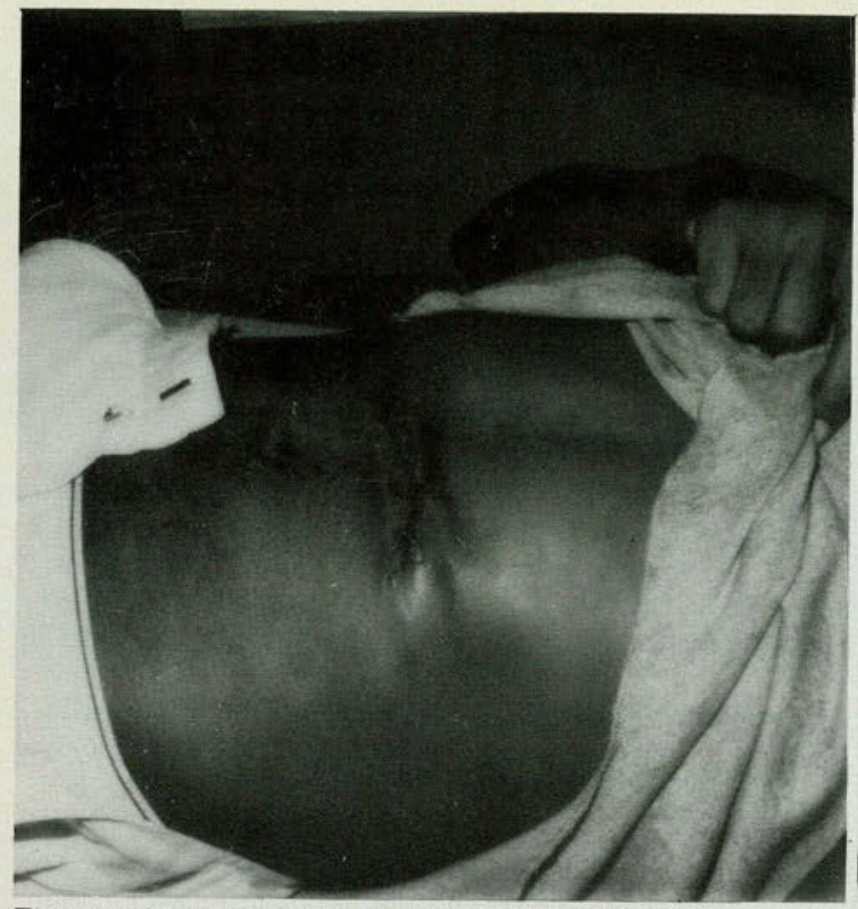

Figs. 1 and 2. Views of patient after excision of lesion.

imal extremities. ${ }^{2-5}$ Clinically, it is a raised, firm, multinodular tumor which often resembles an infected keloid or indurated plaque. It is often bluish and reddish, of firm consistency, and with a tendency to ulcerate as it increases in size. ${ }^{3}$ The lesion is usually slow-growing and locally invasive. A history of antecedent trauma was cited in 16.5 percent of Taylor and Helwig's ${ }^{3} 115$ cases, but may be coincidental. ${ }^{2}$ The local aggressiveness of this tumor is widely recognized. ${ }^{3}$ It may recur in up to half of cases. ${ }^{2}$ Metastasis is rare, with Enzinger and Weiss ${ }^{2}$ suggesting that the rate is less than 1 percent. When metastasis occurs, the lungs are the most common site. ${ }^{2}$

\section{Diagnosis}

The diagnosis should be based on the history, clinical findings, and histologic appearance. ${ }^{2}$ The diagnosis can be confirmed with the use of the histologic criteria of Taylor and Helwig, ${ }^{3}$ which include the distinct storiform, or "cartwheel" pattern, low mitotic rate, and involvement of the cutis and subcutis with bulging of the epidermis. Sometimes, however, the tumor contains myxoid areas ${ }^{2}$ and more mitotic activities. ${ }^{7}$

Dermatofibroma protuberans is uncommon, and unless there is a high index of clinical suspicion, the lesion is easily misdiagnosed. ${ }^{1}$

It must be differentiated from dermatofibroma nonprotuberans in which the lesion does not protrude above the skin. ${ }^{8}$ The microscopic picture in

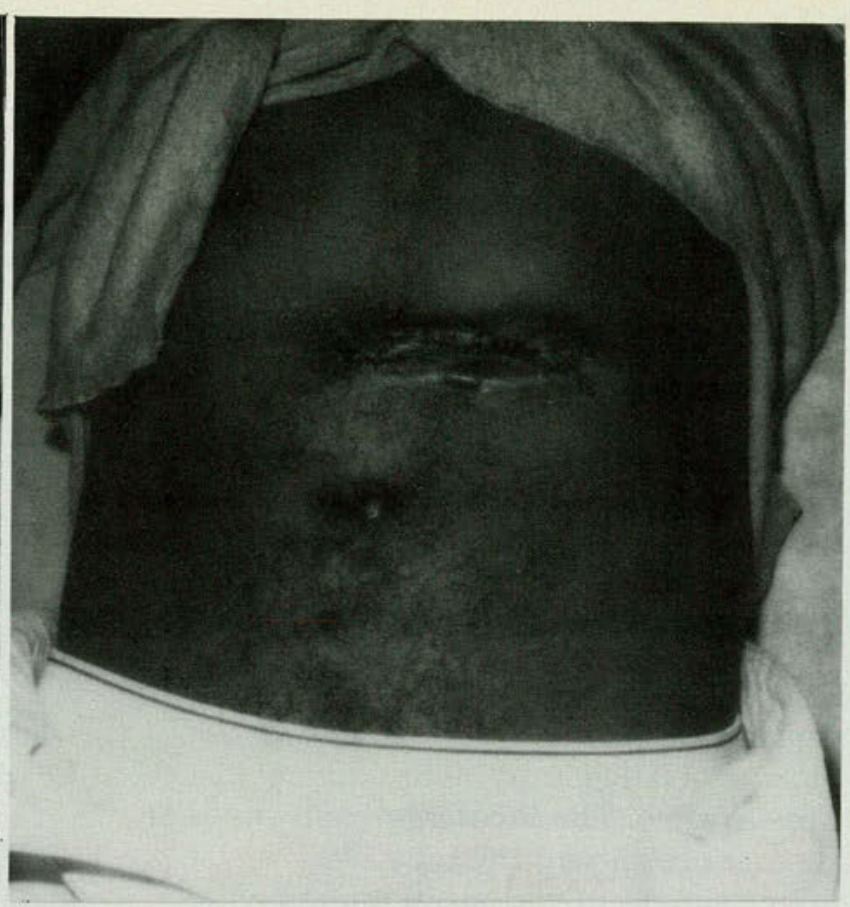

dermatofibroma protuberans is helpful in differentiating it from other dermatologic spindle-cell carcinomas: fibroblastic fibrosarcoma, leiomyosarcoma, schwannoma, amelanotic malignant melanoma, spindle-cell carcinoma, and dermatofibroma.

It is important to differentiate it from fibrohistiocytic tumors. First, according to Enzinger, ${ }^{2}$ "the dermatofibrosarcoma protuberans has a more uniform appearance and smaller cells and displays a more distinct storiform pattern with fewer secondary elements (giant cells, inflammatory cells) than either benign or malignant fibrous histiocytoma." Biopsy should be performed. Second, dermatofibroma protuberans must be differentiated from benign neural tumors, primarily a diffuse form of neurofibroma. Third, it must be differentiated from myxoid liposarcoma.

\section{Recurrence}

Dermatofibroma protuberans is a low-grade sarcoma with a long clinical course, pronounced tendency to progression, and local recurrence. It recurs in up to half of patients. ${ }^{10}$ Prompt, wide local excision is recommended; recurrence rates of 2.05 percent ${ }^{10}$ and 33 percent $^{11}$ have been reported.

Obviously, a conservative approach is not recommended in cases in which an incompletely excised lesion would jeopardize a vital structure. ${ }^{2}$ It is important to note that of over 400 cases documented, less than 1 percent had metastases. ${ }^{12}$ 
According to Enzinger," "The tumor is characterized by a slow and persistent growth over an extended period of time, often several years..." He further states that "in later stages the initial plaque may eventually enter a rapid growth phase and give rise to one or more nodules, thus appearing as the typical 'protuberant lesion." Although the initial tumor is usually asymptomatic, as with many skin diseases, it is a change in symptoms or appearance that causes the patient to come to their physician. ${ }^{3}$

\section{Summary}

A patient suspected of having dermatofibroma protuberans should first undergo biopsy. Once the diagnosis has been made, the lesion should be excised widely and deeply. Extensive surgical excision is the best treatment, since these tumors are radioresistant. Conservative surgery is admissible only when extensive treatment is not feasible. It is important to diagnose the tumor because of the need to surgically excise for this type of locally aggressive tumor.

1. Rowsell, A.R., Poole, M.D., and Godfrey, A.M.: Dermatofibrosarcoma protuberans. The problems of surgical management. Br J Plast Surg 39:262-4, Apr 86

2. Enzinger, F.M., and Weiss, S.W.: Soft tissue tumors. C.V. Mosby Co., St. Louis, 1983
3. Taylor, H.B., and Helwig, E.B.: Dermatofibrosarcoma protuberans. A study of 115 cases. Cancer 15:717-25, Jul-Aug 62

4. Roses, D.F., et al.: Surgical treatment of dermatofibrosarcoma protuberans. Surg Gynecol Obstet 162:449-542, May 86

5. Fletcher, CDM, et al.: Dermatofibrosarcoma protuberans. A clinicopathological and immunohistochemical study with a review of the literature. Histopathology 9:921-38, Sep 85

6. Hess, K.A., et al.: Chemosurgical reports. Myxoid dermatofibrosarcoma protuberans. J Dermatol Surg Oncol 11:268-71, Mar 85

7. Chattopadhyay, T.K., Singh, M.K., and Arunabh: Dermatofibrosarcoma protuberans - a clinicopathological study of ten cases. Jpn J Surg $16: 435-8$, Nov 86

8. Lambert, W.L., et al.: Dermatofibrosarcoma non-protuberans. Description and report of five cases of a morpheaform variant of dermatofibrosarcoma. J Surg Oncol 28:7-11, 1985

9. Bendix-Hansen, K., Myhre-Jensen, O., and Kaae, S.: Dermatofibrosarcoma protuberans. A clinico-pathological study of nineteen cases and review of world literature. 17:247-252, 1983

10. Burkhardt, B.R., Soule, E.H., and Winkelmann, R.K.: Dermatofibrosarcoma protuberans. Study of 56 cases. Am J Surg 111:638, 1966

11. Penner, D.W.: Metastasizing fibrosarcoma protuberans. Arch Surg 62:391, 1976

12. Brenner, W., et al.: Dermatofibrosarcoma protuberans metastatic to a regional lymph node. Cancer 36:1897, 1975

At the time this paper was written, Dr. Norman was a resident in dermatology in Medford, Massachusetts; Richard K. Brown, M.D., was the residency director. Dr. Bennett is a general surgeon on the staff of University General Hospital (UGH) in Seminole, Florida. Dr. Drehsen is a plastic surgeon and is on the consulting staff of UGH. Dr. Deem was an intern on the staff of UGH and is now in private practice of family medicine in Tampa, Florida.

Dr. Norman, 22 Mill Street, Suite 210, Arlington, Massachusetts 02174 . 


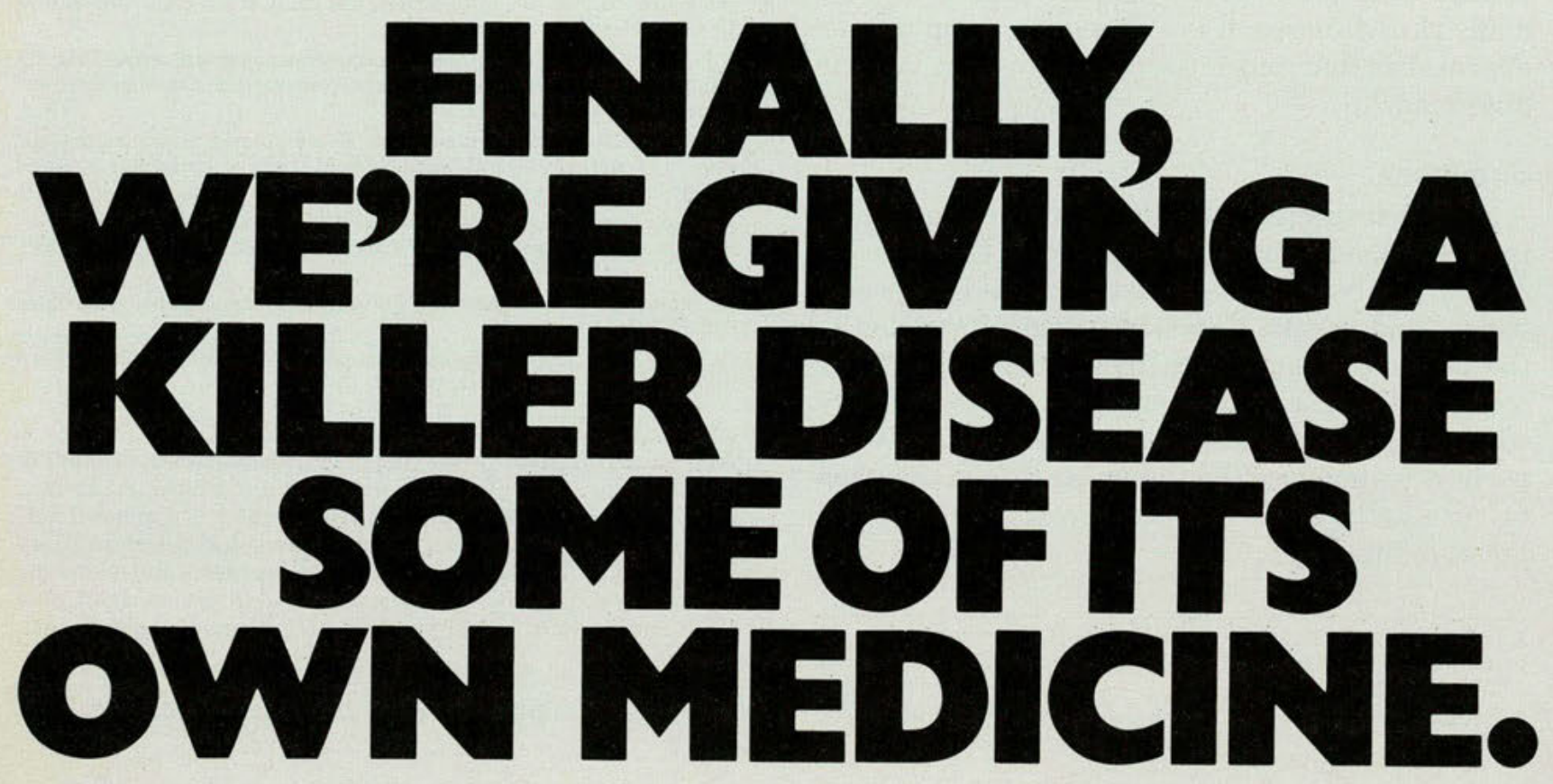

A disease that once put an end to its victims, may soon be put to an end itself.

The disease, carnitine deficiency, destroys the body's ability to produce carnitine, a muscle-fueling substance. Until recently, carnitine deficiency meant certain disability. Often, it meant death.

In the past year, though, carnitine replacement therapy-developed with funding from the Muscular Dystrophy

Association-has allowed fully half the patients treated to resume normal lives.

Carnitine replacement therapy is one of the most encouraging developments in MDA's fight against 40 neuromuscular diseases. And for one of those dread diseases, it could be the beginning of the end.

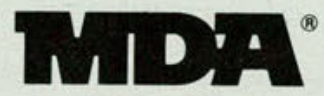

Muscular Dystrophy Association, Jerry Lewis, National Chairman 

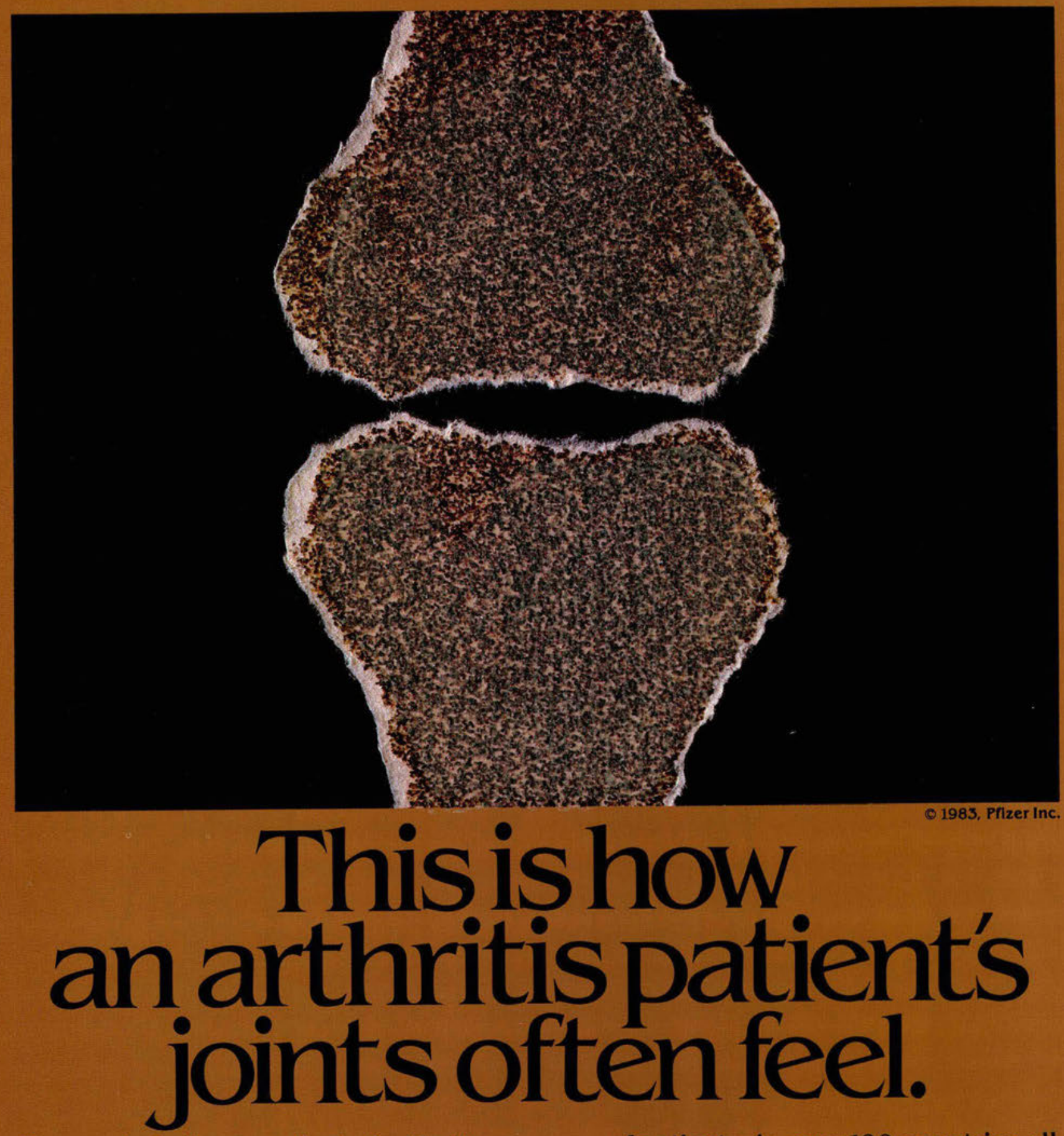

You can help these patients feel better with one-a-day FELDENE ${ }^{*}$ (piroxicam). For good reasons:

- it's effective-proven relief of the pain and inflammation of rheumatoid arthritis and osteoarthritis ${ }^{1}$ in millions

of patients, in over 100 countries all around the world.

- it's efficient-once daily, 20-mg dose provides round-the-clock relief, improves compliance and remains effective during long-term therapy.

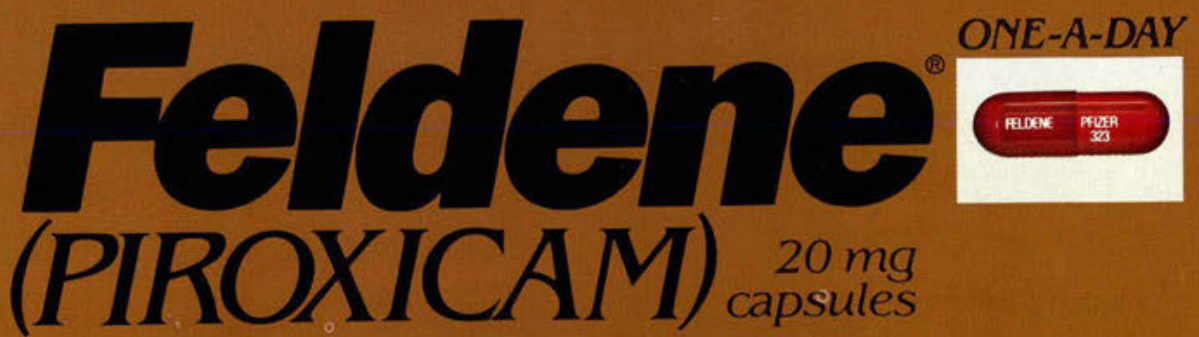




\section{Feldene (PIROXICAM) $)_{\text {apong }}^{20 m a s}$}

\section{Prescribe one $20 \mathrm{mg}$ capsule daily for convenience and compliance}

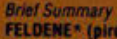

RELENE* (piroxicam) Capsules

COMTRaimoications: FEL OENE (Ditoxicam) should not be used in patients who have previously exhibitied hypersensitivily fividuats with the syndrome comprised of bronchospasm, nasal polyps and angioedema precipitated by aspirin

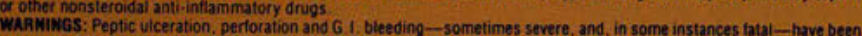
reported with patients receiving FELDENE. II FELDENE must De given to patients with a history of upDer gastrointestinal tract disease, ine patient should be under close supervision (see ADVEASE REACTIONS

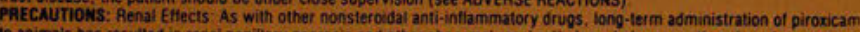
to animais has resulted in renal papilary necrosis and other abnormal renal pathology In humans, there have been reports of acule interstitiai neghritis with hematuria, proteinuria, and occasionally, nephrotic syndrome.

flow oc biond form of renai toxictity has been seen in patients with prerenal conditions leading 10 a reduction in renal blood now or blood volume, where the renal prostaglandins have a supportive role in the maintenance of renal pertusion. In these overt renal decompensation. Patients at greastest risk of this reaction are those with impaired ienal function, heart lailure. iver dystunction, inose taking diveretics, and the eiteriy.

Because of exiensive renal excretion of oiroxicam and its biotranstormation products lless than $5 \%$ of the daily dose excreted unchanged). lower doses of piroxicarn should be anticipated in patients with impaired renal function, and they should be caretuly monitorec

Although other nonsteroidal anti-inflammatory drugs do not have the same direct eflect on platelets that asoirin does. all orrugs innibiting prosstaglandin biosyntresis do interfiere with platelet function to some degree

Because of reports ot adverse eye findings with nonsteroidal ant-inflammatory agents, it is recommenoed that patients who develop visual complaints during treatment with FELDENE have ophthalmic evaluation

15\% math other nonsteroidal anti-inflammatory drugs, borderline elevations of one or more liver tests may occur in up to

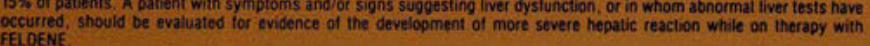

Severe hepatic reactions. including laundice and cases of tatal hepatitis have been reported with FEL DENE. Aithough such reactions are rare, if abnormal liver tests persist or worsen. if cininical signs ane symptoms consistent with iver dis. ease develog, or it systemic manilestations occut ie. q., eosinophilia, rash, eic.). FEL OERE shoulid be discontinued. (Set aiso AOVERSE REACTIONS.

Athough at the recommended dose of $20 \mathrm{mg} / \mathrm{day}$ of FEL DENE increased fecal blood loss due to gastrointestinat irritation did not occur, in about $4 \%$ of the patients treated with fFLLENE alone or concomitantily with aspirin, reductions in he moplobin and hematocrit values were obsservec

Should be beral ederma has been observed in approximately $2 \%$ of the patients treated with FELDENE. Therefore, FELOENE should be used with caution in patients with heart tailure, hypertension or other conditions predisposing to fluvid retention.

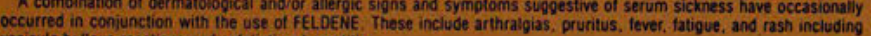
vesiculo bullous reactions and extoliative dermatitis

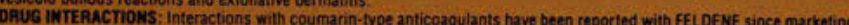
Theretore. ohysicians should closely monitor patients for a change in dosager requirements when administerimg FELDEFE to patients on coumarin-type anticoagulants and other highly protein-bound drugs.

Plasma levels of piroxicam are depressed 10 approximately $80 \%$ of their normal values when FELDENE is acministereo in conjunction with aspirin $(3900 \mathrm{mg} /$ day). but concomitant acministration of antacios has no etfect on piroxicam plassm

levels. Nonsteroidal anti-nflammatory agents, including FEL DENE, have been reporteo to increase steacy state plasma lithium evelis It is recommended that plasma lithium levels be monitored when initiating, adjusting and discontinuing fFELDENE. Carcinopenessis. Chronic Animal Toxicily and Impairment of fertility: Subacute and chronic toxicity studies have been Thried out in rats, mice, dogs, and monkey

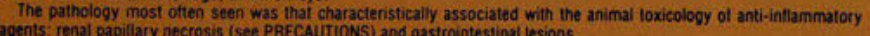

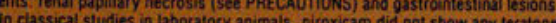

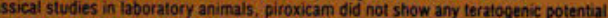

Reproductive studies reveaied no impairment of tert tity in snimats.

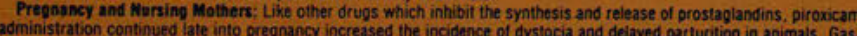
rointestinat tract toxicity was increased in pregnant temales in the last trimester of preanancy compared in animals. Gas lemales or temales in earilier trimesters of pregnancy

FELDENE is not recommended tor use in nursing mothers or in pregnant women because of tine animat tindings and sinct salery for such use has not been estabished in humans

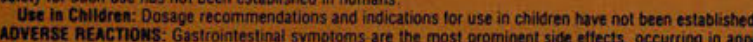

AOVERSE REACCIOWS: Gastrointestinal symptoms are the most prominent side effects, occurring in approximately $20 \%$ of the parients, which in most instances did not interfere with the course of therapy of the patients experiencing gastio-
intestinal side stlects, approximately $5 \%$ discontinued therapy with an overall incidence of peptic ulceration of about $1 \%$.
Adverse reactions are listed below by body system for all patients in clinical trials with FELDENE (piroxicam) at doses lacidence Greater Than $1 \%$ : The following adverse reactions occurred more frequently than 1 in 100 Incidence Greater Than 1W: The following adverse reactions occurred more frequently than 1 in 100 .
Gastronfestinal: Stomatitis, anorexia, epigastric distress: nausea: constipation, abdominal discomtort, flatulence, of abical decreases in ham

Dermatologic: pruritus, ras

Central Nervous System: dizziness, somnolence, verting

Urogenital: BUN and creatinine eievations (see PRECAUTIONS)

Body as a whole: headache, malaiso

Special Senses: tinaitus

Cardiovasculai Respiratory edema (see PRECAUTIONS)

- Reactions occurring in $3 \%$ to $9 \%$ of patients treated minth FELLENE

Reactions occurting in $1 \%$ to $3 \%$ of patients are unmarked.
ineidence Less Than 18 (Causal Relationship Probatiel. The

Incidence Less Than $1 \%$ (Causat Relationship Probable): The following adverse reactions occurred less trequently than 100. The probability exists that there is a causai relationship between fELOENE and these reactions

Gastrointestinal: liver function abnormalities, jaundice, hepatitis (see PAECAUTIONS), vorniting, hemalemesis, melena

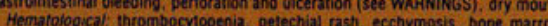

epistaxis

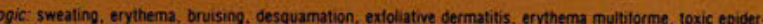
mail necrolysis, Stevens-Johnson syndrome, vesicvilo buillous reactions, photoallergic skin reactions

Central Nervous System; depression, insomnia, nervousness
Urogenitat: hematuria, proteinuria, interstitial nephritis, renai tailure, hyperkalemia, glomerulitis, papillary necrosis, nephrotic syndrome (see PRECAUTIONS)

Body as a Whole: pain (colic), fever, flu-like syndrome (see PRECAUTIONS)

Cardiovascutar:Respiratory: hypertension, worsening of congestive heart tailure (see PAECAUTIONS), exacerbation of angina

Metabolic hypoglycemia, hyperglycemia, weight increase, weight decrease

Hypersensitivity anaphylaxis, bronchospasm, urticaria/angioedema, vasculitis, 'serum sickness' (see PRECAUTIONS) than 1 in 100 , but a causal relationship between FEL DENE and the reaction could not be determined

Gastrointestinat: pancreatius

Dermatologic: onycholysis, loss of hair

Central Nervous System: akathisia, hallucinations, mood alterations, dream abnormatities, mental confusion, paresthesias

Urogenital System: dysuria

body as a Whole: weaknes:

(yspne:

OVERODOSAGE: In the event treatment for overdosage is required. the lone olasma half-ilite of piroxicam should be consid. ered. The absence of experience with acute overdosage precludes characterization of sequelae and recommendations of specitic antiootai efficacy at this time. It is reasonable to assume that the standard measures of gastric evacuation and general supportive therapy would appiy in adotion to sugpontive measures, the use of activated charcoai may effectively reduce the ausorption ano reabsorption of piroxcam. Experiments in dogs have dernonstrated that the use of multiple-dose treatments with activateo charcoal could reduce the hali-life of piroxicam elimination from 27 hours (without charcoal) to 11 hours and reduce the systemic bioavailability of piroxicam by as much as $37 \%$ when activated charcoal is given as late as 6 hours after administration of piroxican

De Arthritis, Osteoarthritis: It is recommended that FELDENE therapy be iniIed and maintained at a single daily dose of $20 \mathrm{mg}$. II desired. The daily dose may be divided

Dosage recommendations and indications for use in children
More detalied professional information available on reouest.

c1982. Plizer inc.

Reterences: 1. Siegmeth W: Serum concentrations of piroxicam in relation to its clinical effect in patients with chronic $D D$ lyarthntis (trans). Wien Med Wochenschr 130:31-35. 1990. 2. Tausch: Placebo-controlled study of piroxicam in the trea! ment of rheumatoid arthritis. Am J Med (report) 72:18-22. February 16. 1982 